\title{
The Effects of Temperature on the Mechanical Performance in Fatigued Single Muscle Fibers of the Frog Induced by Twitch and Tetanus
}

\author{
Naoko INAMURA, Ayako FUJISIGE, Shinichi MIYAKE, Akira ONO, and Teizo TSUCHIYA \\ Department of Biology, Faculty of Science, Kobe University, Kobe, 657-8501 Japan
}

\begin{abstract}
Muscle fatigue induced by consecutive twitches or tetani was studied in single skeletal muscle fibers of the frog, Rana japonica. The fatigue by twitch appeared sooner after the start of stimulation at lower temperatures $\left(2-5^{\circ} \mathrm{C}\right)$ than at higher ones $\left(15-20^{\circ} \mathrm{C}\right)$, while the fatigue by tetanus appeared sooner at higher temperatures. When a twitch-fatigued fiber was bathed in a solution with caffeine $(15 \mathrm{mM})$, the contracture force was much higher than the fatigued force, while in tetanus fatigue, the force by caffeine was not different from the fatigued force. The length-force relation in fatigued fibers was compared with that in pre-fatigue at low and high temperatures. It was noticed that the ascending limb of the length-force curve in fatigued fibers by twitch
\end{abstract}

was lower than that in pre-fatigue at the low temperatures; namely, the fatigue by twitch was more marked in shorter muscle length, while no marked change in the length-force relation was detected in the tetanus fatigue at the low and high temperatures. The maximum shortening velocity, measured by the slack test, decreased in both types of fatigue. These results suggest that the fatigue by twitch may be mainly due to the failure of activation of the contractile system, while in the fatigue by tetanus, the rate of the interaction between actin and myosin may be impaired due to the change in intracellular chemical environment. [Japanese Journal of Physiology, $50,49-57,2000]$

Key words: muscle fatigue, skeletal muscle, twitch, tetanus. It has been known that the ability of the mechanical performance of skeletal muscles deteriorates with prolonged activity in terms of force production, shortening velocity and power output. This reduced ability of performance is called "fatigue," and has been defined in various ways. It is generally defined to be the state of the muscle in which force declines reversibly from the maximal ability with prolonged activation. Fatigue might be due to a failure anywhere along the path for the conduction of the information which finally produces the interaction of actin and myosin, such as $\alpha$ motoneurons, the end-plate area, surface membrane of the muscle cell, transverse tubules, sarcoplasmic reticulum and cross-bridges. Among these possibilities, numerous studies have been done on isolated muscle preparations to determine the cause of fatigue within the muscle cell itself. Evidence has been presented to show that the decrease in mechanical performance during fatigue is due to insufficient activation of the contractile system [1-5]. Several possibilities can be thought of to account for this effect; for example, reduced sensitivity to $\mathrm{Ca}$ [6-8], a decrease in the amount of $\mathrm{Ca}$ released from the sarcoplasmic reticulum $[5,7]$, and the impairment of the inward spread of excitation into the muscle fiber $[1,9]$. In the latter mechanism, the center of the fiber may not be activated by the propagated impulse during repeated stimulation.

On the other hand, it is known that the repetitive activation of a muscle cell leads to the change in the intracellular concentration of the metabolites and ions, such as the decrease in concentrations of ATP and creatine phosphate $(\mathrm{PCr})$ and increase in the concentrations of ADP, lactic acid and $\mathrm{H}^{+}[2,10-12]$. Further,

Received on March 29, 1999; accepted on November 17, 1999

Correspondence should be addressed to: Teizo Tsuchiya, Department of Biology, Faculty of Science, Kobe University, Kobe, 657-8501 Japan. Tel and Fax:+81-78-803-5718, E-mail: tsuchiya@kobe-u.ac.jp 
the results obtained in experiments on skinned muscle fibers showed that the above-mentioned ATP hydrolysis products really affected both maximum shortening velocity and isometric force $[8,13]$.

The present experiments have been performed to further elucidate the mechanism of muscle fatigue. The specific aim of this study has been to examine the effects of temperature on the fatigue induced by consecutive twitches or tetani in order to understand the mechanism of fatigue.

\section{METHODS}

Muscle fiber preparations and solutions. All experiments were performed with single fast-muscle fibers (diameter $80-120 \mu \mathrm{m}$ ) isolated from the tibialis anterior muscles of the frog, Rana japonica, as described previously [14]. The frogs were sacrificed by decapitation followed by destruction of the spinal cord. Small clips of aluminum foil [15] were tied to tendons on both sides (Fig. 1A). These connectors were attached close to the fiber insertions, so that the length of tendinous tissue between the connector and the insertion was less than $0.1 \mathrm{~mm}$. The Ringer solution had the following composition (mM): $\mathrm{NaCl}, 115$; $\mathrm{KCl}, 2.0 ; \mathrm{CaCl}_{2}, 1.8 ; \mathrm{Na}_{2} \mathrm{HPO}_{4}-\mathrm{NaH}_{2} \mathrm{PO}_{4}, 2.0$; and $\mathrm{pH}$ 7.0. In some experiments, caffeine $(15 \mathrm{mM})$ was added to the Ringer solution for full activation of the fiber.

Experimental setup. The single-fiber preparation was mounted horizontally in an acrylic plastic chamber by hooking the connectors to a force transducer and a servomotor, respectively (Fig. 1B). The chamber contained two parallel platinum plates on either side of the bath for the electrical stimulation. The fiber was stimulated by passing rectangular current pulses $(0.2 \mathrm{~ms}$ duration) between two platinum plate electrodes that were placed symmetrically on either side of the fiber approximately $4 \mathrm{~mm}$ apart from each other. The stimulus strength was $30 \%$ above the threshold. A single pulse or a train of pulses was delivered to induce a twitch or a fused tetanus of $1 \mathrm{~s}$ in duration. The pulse frequency $\left(18-25 \mathrm{~Hz}\right.$ at $2-5^{\circ} \mathrm{C}$ and $40-55 \mathrm{~Hz}$ at $15-20^{\circ} \mathrm{C}$ ) during the tetanus was adjusted appropriately to obtain mechanical fusion under the various experimental conditions. The temperature of the circulating solution in the bath was controlled by a thermo-electric device (Coolnix, Yamato Kagaku Co.) and the solution was circulated through the chamber at a rate of $2 \mathrm{ml} / \mathrm{min}$ with a peristaltic pump. All the experiments were performed either at low temperatures $\left(2-5^{\circ} \mathrm{C}\right)$ or high temperature $\left(15-20^{\circ} \mathrm{C}\right)$.

The sinusoidal length change $(1 \mathrm{kHz}, 0.1 \%$ of the
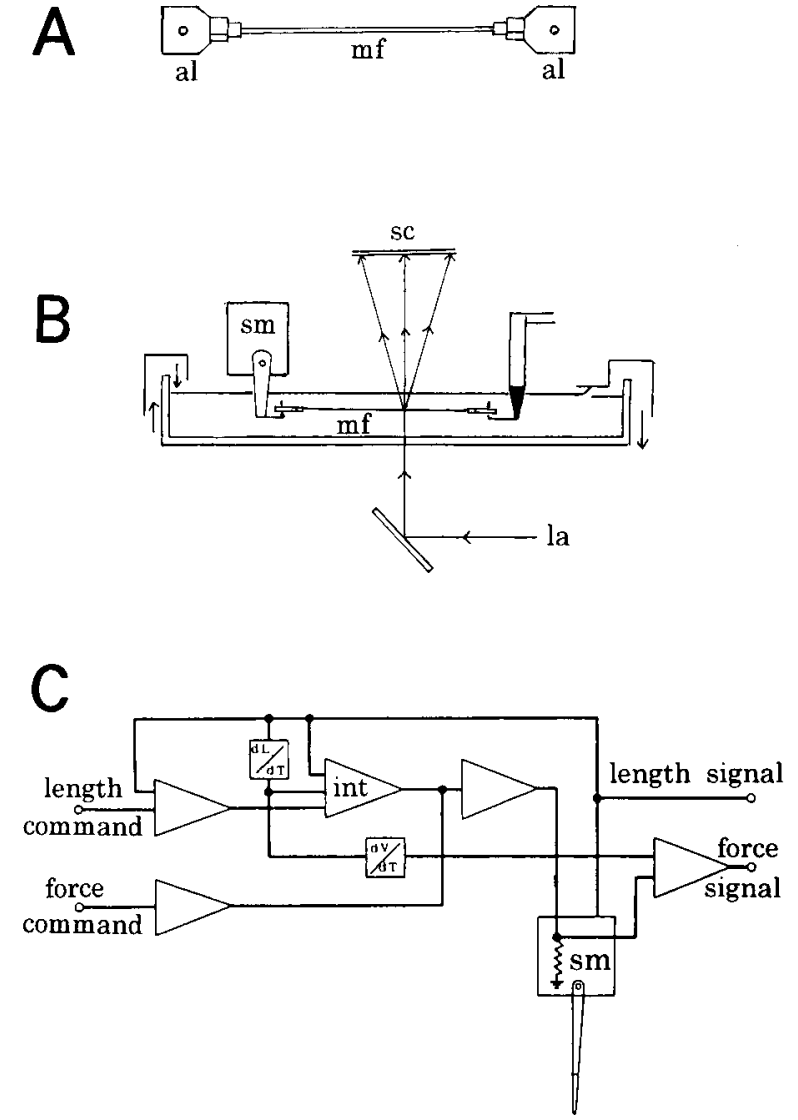

Fig. 1. Schematic drawing of the experimental setup. A: A single fiber preparation ( $\mathrm{mf}$ ) with aluminium tendonclips (al) attached at both fiber ends. B: Experimental bath. Each end of a fiber preparation (mf) was attached to the arm of a servomotor (sm) and force transducer (ft). Sarcomere spacing was measured by the laser (la) diffraction pattern on the screen (sc). C: Diagram of the electronic circuit to drive the servomotor (sm) and monitor muscle length and force. Force change was measured by the electronic circuit of the motor-controller or by the force transducer, to which the fiber end was attached.

resting fiber length) was applied to the preparation with a servomotor (G-100PD, General Scanning Inc. or Dual Mode Servo 300, Cambridge Technology) to measure the stiffness. The resulting force change created by the sinusoidal length change was taken as the relative stiffness. The force of the preparation was measured by a force transducer (AE801, Sensonor) with a compliance of $0.1 \mathrm{~mm} / \mathrm{N}$ and a resonant frequency of about $5 \mathrm{kHz}$ or by the feedback signal from the servomotor (Fig. 1C). The force change was recorded with a digital oscilloscope (type 310, Nicolet). Sarcomere lengths of the fibers were measured at rest in the middle of the fiber by diffraction of $\mathrm{He}-\mathrm{Ne}$ laser light and were adjusted to $2.2 \mu \mathrm{m}$ unless otherwise stated. The diffraction pattern was displayed on a screen $12 \mathrm{~cm}$ distant from the fibers (Fig. 1B). The sarcomere spacing was fairly uniform along the fiber 


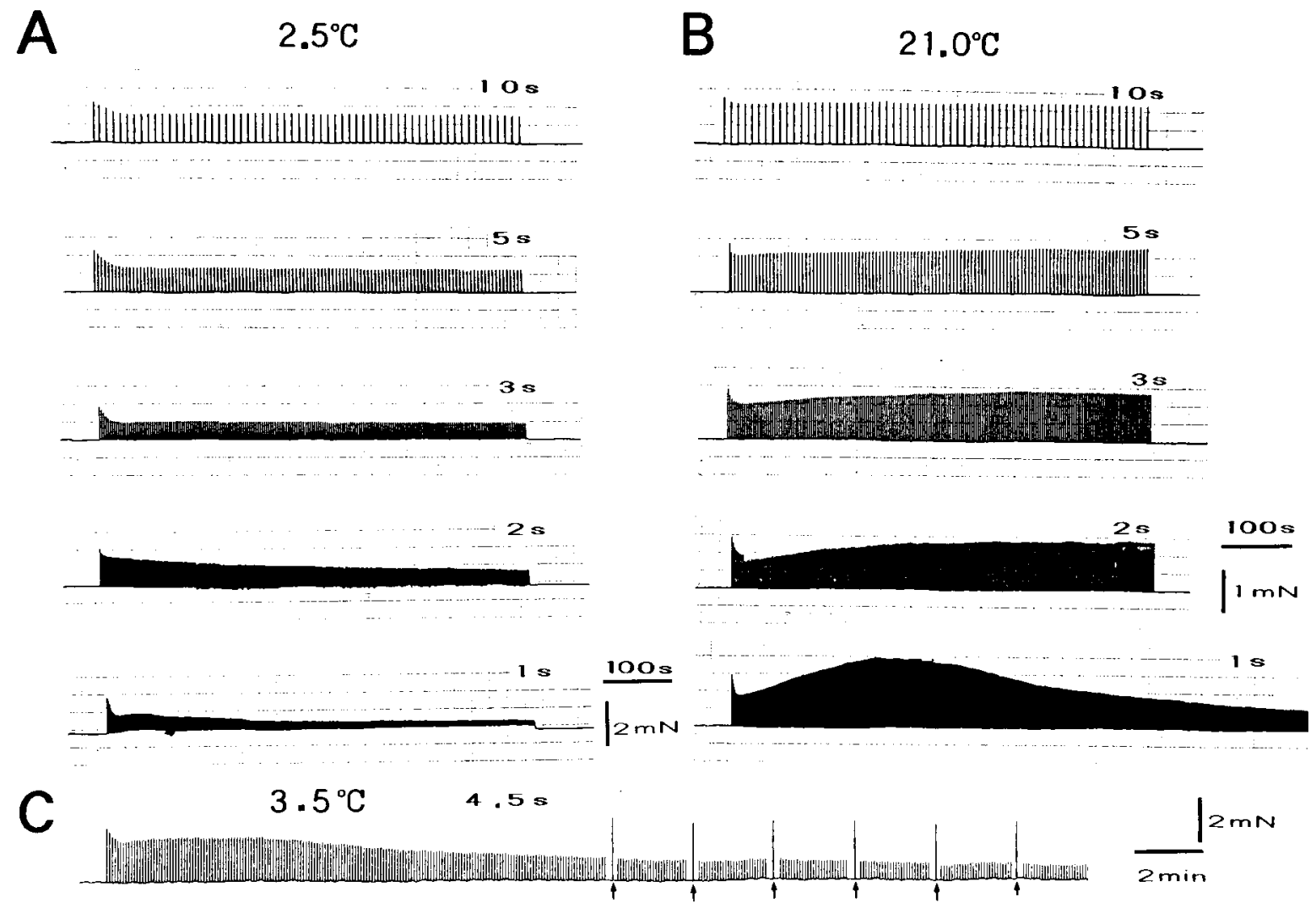

Fig. 2. Force records showing the development of fatigue by consecutive twitch stimulation at low (A, C) and high (B) temperatures. The temperature and stimulation intervals and are shown. C shows the record in which tetanic contractions (arrows) were induced in the course of consecutive twitches for the measurement of the shortening velocity.

length except for the end regions.

\section{RESULTS}

\section{The effect of fatigue by twitch on force at low and high temperatures}

The change in force over time by successive twitch stimulation was measured at the low (Fig. 2A) and high temperatures (Fig. 2B). The interval of each stimulus was changed in the range of $1-10 \mathrm{~s}$ at both temperatures. After the stimulation was started, the decrease in force was initially rapid and then gradual (negative staircase) at low temperatures, while the initial rapid decrease was followed by a gradual increase (positive staircase) at high temperatures. When the stimulus interval was $1 \mathrm{~s}$, this positive staircase gradually disappeared and the force again started to decrease. It was noted that the fatigue by twitch was marked at low temperatures, especially during stimulation with short intervals, such as being $10 \%$ of the initial force at $10 \mathrm{~min}$ after the start of stimulation, while at high temperatures, an even positive staircase, as mentioned above, was observed. In Fig. 2C, one example of the record in which 1-s tetani were superimposed in the course of twitch stimulation is shown.
The shortening velocity was measured in these tetani (see below).

\section{The effect of fatigue by tetanus on force at low and high temperatures}

The change in force over time with successive tetanic stimulation was measured at the low (Fig. 3A) and high temperatures (Fig. 3B). The interval between the stimulation was changed in the range between $30 \mathrm{~s}$ and $5 \mathrm{~min}$ for both temperature ranges. At low temperatures, tetanic force was steady after a slight decrease in the first several contractions at the intervals of 2.5 and $5 \mathrm{~min}$, but at shorter intervals, the force continued to decrease. At the interval of $30 \mathrm{~s}$, the force decreased to $50 \%$ of the initial force after $20 \mathrm{~min}$.

At high temperatures, the decrease in force in the successive contractions appeared sooner and more marked than at low temperatures, the force being reduced to less than $10 \%$ of the initial force at $20 \mathrm{~min}$ at the interval of $30 \mathrm{~s}$. By comparing force responses at both temperatures, fatigue by tetanus is more marked at higher temperature. 
A

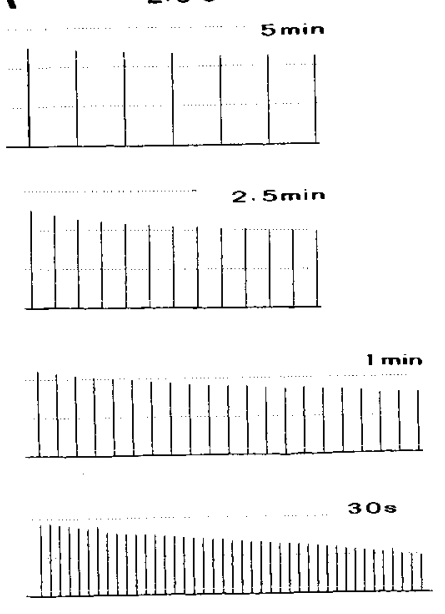

B
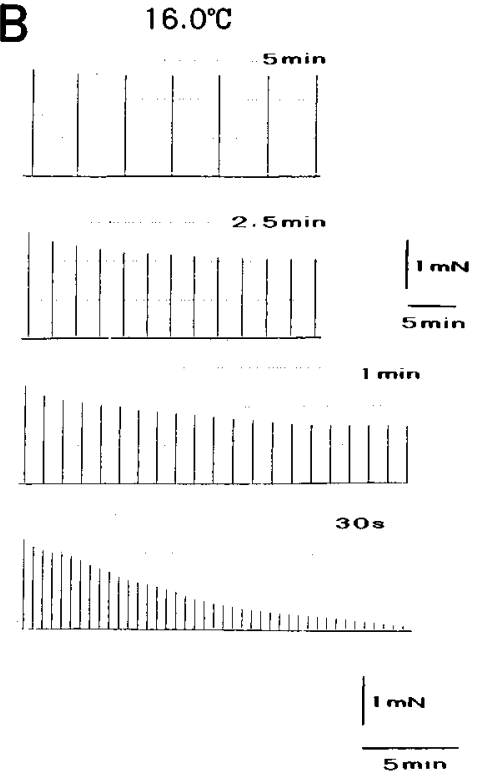

Fig. 3. Force records showing the development of fatigue by consecutive tetanic stimulation at low (A) and high (B) temperatures. Stimulation intervals and temperatures are shown. The force and time bars in the middle are for the records with the stimulation interval of 5 and $2.5 \mathrm{~min}$ and the bottom ones for that with $1 \mathrm{~min}$ and $30 \mathrm{~s}$. Note that the fatigue by tetanus appeared sooner at the higher temperature.
A

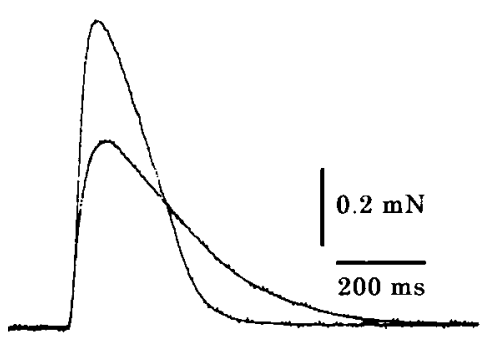

C

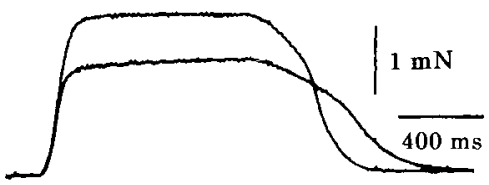

B

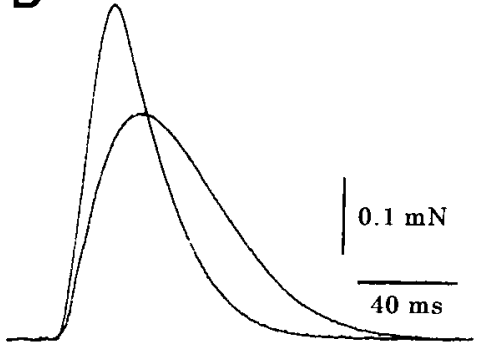

D

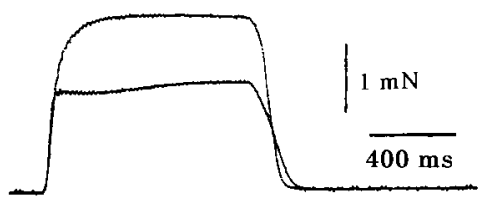

Fig. 4. The comparison of force records before and after the development of fatigue. Fatigue was induced by twitch (stimulation interval, $5 \mathrm{~s}$ ) (A, B) or tetanus (stimulation interval, $1 \mathrm{~min})(\mathbf{C}, \mathbf{D})$ at $\operatorname{low}\left(\mathrm{A}, 2.5^{\circ} \mathrm{C} ; \mathrm{C}, 2.5^{\circ} \mathrm{C}\right)$ and high $\left(\mathrm{B}, 21.0^{\circ} \mathrm{C} ; \mathrm{D}, 16.0^{\circ} \mathrm{C}\right)$ temperatures. In each panel, the lower is the force after fatigue and the higher is the one before fatigue. The fatigued force was recorded at $5 \mathrm{~min}$ in twitch and $10 \mathrm{~min}$ in tetanus after the start of consecutive stimulation.

\section{The time course of force developed in twitch and tetanus in fatigued fibers}

The time courses of the force development and decay in each twitch and tetanus in fatigued fibers were compared with those in the control at the low and high temperatures (Fig. 4). A reduction in force was observed for both twitch (Fig. 4A and B) and tetanus (Fig. 4C and D) as shown in Figs. 2 and 3. In fatigue caused by twitches, the rate of declining force was slowed at low temperatures, while both the rate of rise and fall were slowed at high temperatures. In fatigue caused by tetanus, the decrease in the rate of decline was observed at low temperatures, while at high temperatures, the force reached at a constant level sooner and decayed more slowly in the fatigued fiber.

\section{Force development by caffeine in fatigued fibers}

Caffeine is known to release calcium directly from the sarcoplasmic reticulum leading to force development. If fatigue is induced by impairing some mechanism in the excitation-contraction coupling, the force induced by caffeine may not be affected. In fatigue caused by the repeated twitches shown in Fig. 5, in which tetanic contractions were interposed, force was reduced significantly at $15 \mathrm{~min}$ after the start of stimulation in both twitches and tetani in both temperature ranges. When $15 \mathrm{mM}$ caffeine was applied, the muscle developed much larger force than the fatigued twitch and tetanus force at both low and high temperatures. In contrast, in fatigue caused by repeated tetani (Fig. 

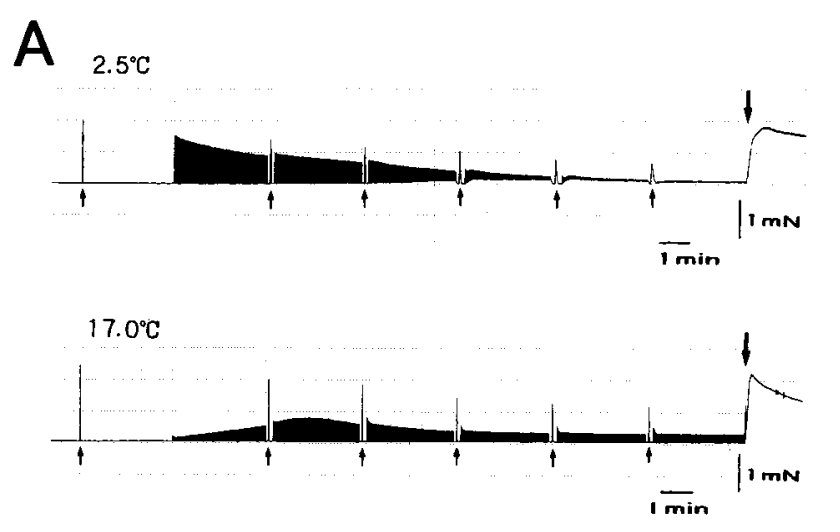

$\mathrm{B}_{2.55^{\circ}}$

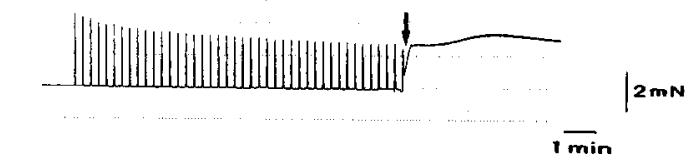

$17.0^{\circ} \mathrm{C}$

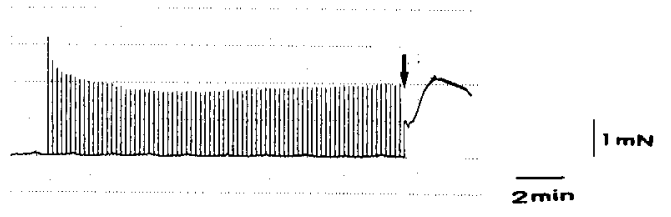

Fig. 5. Force induced by $15 \mathrm{mM}$ caffeine after the fatigue by consecutive twitches (interval, $2 \mathrm{~s}$ at $2.5^{\circ} \mathrm{C}, 1 \mathrm{~s}$ at $\left.17.0^{\circ} \mathrm{C}\right)(\mathrm{A})$ and tetanus (interval, $\left.30 \mathrm{~s}\right)(\mathrm{B})$ at low and high temperatures. In $A$, tetanic contractions (small arrows) were interposed to compare with caffeine contracture. The large arrows show the time of the application of caffeine. Note that, in A, the force by caffeine is much higher than the twitch-fatigued force and the interposed tetanic force, while in B, the force by caffeine is nearly the same as that just before the application of caffeine.

5B), the force developed by $15 \mathrm{mM}$ caffeine was nearly the same as that immediately before the application of caffeine and was also lower than the initial force in both temperature ranges, suggesting that the main cause of fatigue induced by twitch and tetanus might be different.

\section{Length-force relation in fatigued fibers}

The length-force relation was obtained by measuring the isometric force at different sarcomere lengths (Fig. 6). Initially the sarcomere length was set at $2.2 \mu \mathrm{m}$ by laser diffraction in the middle of the fiber and the isometric force was measured. Then, the preparation was stretched or released to a given muscle length and stimulated. The sarcomere length was calculated from the amplitude of the stretch or release from the initial muscle length. The force at each length was plotted by the relative value to the maximum force at the sarcomere length around 2.0-2.4 $\mu \mathrm{m}$. The typical results are shown in Fig. 6. In the fatigue induced by successive twitches $(2-\mathrm{s}$ interval) at low temperature (Fig. 6A), the descending limb was not significantly different from the control. In the ascending limb, however, there was a large difference between the fatigue and control. The force of the fatigued fiber was much lower than the control such that at the sarcomere length of $1.6 \mu \mathrm{m}$, the fatigued force was less than $10 \%$ of the maximum, while the control force was about $65 \%$. At high temperature (Fig. 6B), the difference mentioned above in the ascending limb was less noticeable than at low temperature.

In fatigue induced by successive tetani (30-s interval) (Fig. 6C, D), the ascending limb was a little lower than the control in both temperature ranges but the difference was not as large as that of twitch-fatigue (Fig. 6A). There was no noticeable difference between the fatigue and control in the descending limb in both temperature ranges.

\section{Maximum shortening velocity measured by the slack-test}

The effects of fatigue on maximum shortening velocity were examined by the "slack-test" method. The length steps of several amplitudes were applied to slack a fiber to zero force, and the time for the force to start to rise from the zero level was measured. In the example records in Fig. 7, the amplitude of a length step was the same as in the control (Fig. 7A, C) and tetanus fatigue (Fig. 7B, D) but the time to start rising was longer for the fatigue (cf. lower traces in Fig. 7C and D), suggesting that the shortening velocity is slower in the fatigued fiber. The amplitudes of the length steps and corresponding time for the force rise were plotted, and the shortening velocity was obtained from the slope. The measurements were made on twitch-fatigued fibers (Fig. 8A) $(2.5,4$, and $5.5 \mathrm{~s} \mathrm{stim-}$ ulation intervals) and tetanus-fatigued fibers (Fig. 8B) (20, 40, and 60 s stimulation intervals). The shortening velocity of the twitch-fatigued fibers was measured during tetanic contraction interposed in the course of repeated twitches (Fig. 2C). The velocity, both in twitch-fatigued and tetanus-fatigued fibers, gradually deceased with the shorter interval of stimulation. The decrease was about $40 \%$ in twitch-fatigued fibers at the stimulation interval of $2.5 \mathrm{~s}$ and $30 \%$ in tetanus-fatigued fibers at the interval of $20 \mathrm{~s}$ as compared with the pre-fatigue value. 

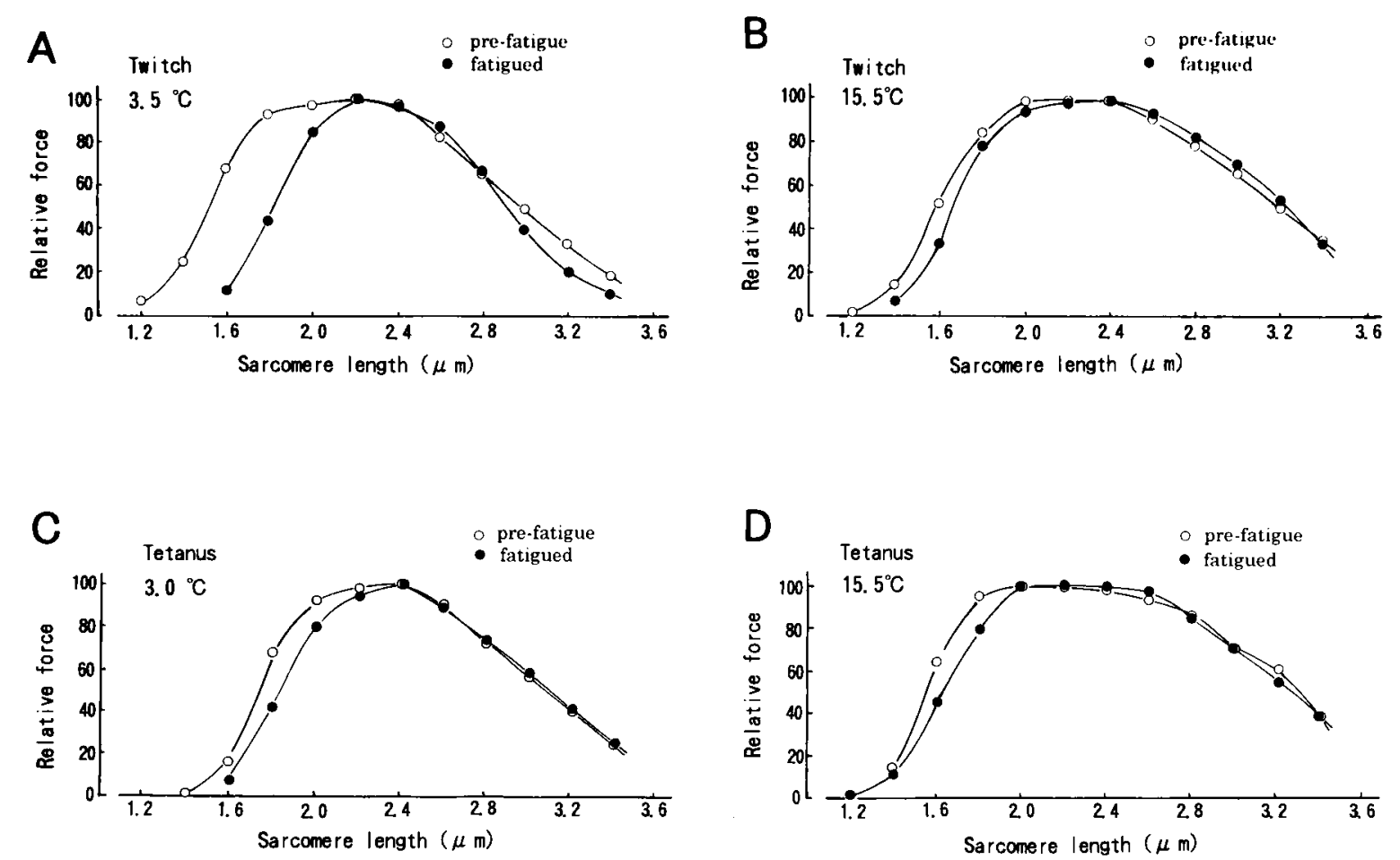

Fig. 6. Length-force relation in twitch fatigue (stimulation interval, $2 \mathrm{~s}$ ) at low (A) and high (B) temperatures and in tetanus fatigue (stimulation interval, $1 \mathrm{~min}$ ) at low (C) and high (D) temperatures. The meaning of the sym-

bols of data points and the temperatures are shown. Force is shown as relative to the maximum value. Note the large difference in the ascending limb in $A$.

\section{A}

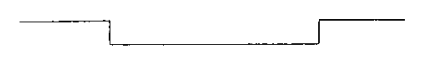

B
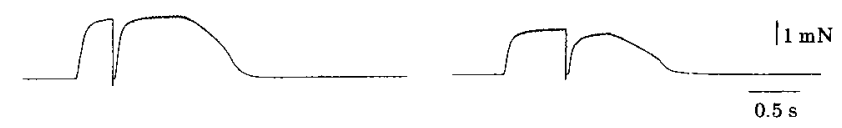

C

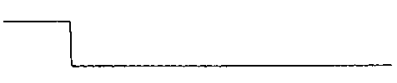

D
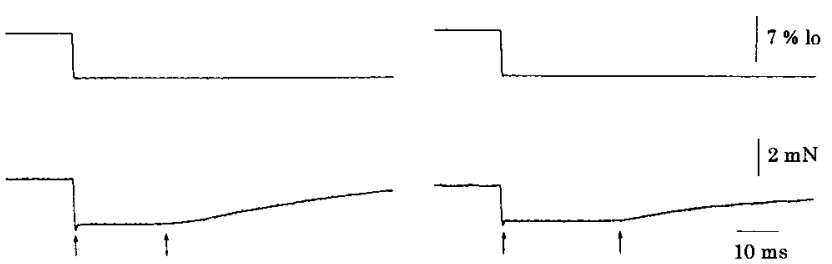

Fig. 7. Example records in the slack test to measure the maximum shortening velocity. Fatigue was developed by consecutive tetanic stimulation (interval, $1 \mathrm{~min}$ ) for $10 \mathrm{~min}$ at $16^{\circ} \mathrm{C}$. A: slow time-base record in pre-fatigue; $\mathbf{B}$ : slow time-base record in fatigue; $\mathbf{C}$ : fast time-base record in pre-fatigue; D: fast time-base record in fatigue. In each panel, the top is length and the bottom is force records. The length steps used are same (7\% of a fiber length) in A-D. The time between first and second arrows in C, D shows the duration of unloaded shortening of a fiber. Note that the duration of unloaded shortening is shorter in pre-fatigue $(C)$ than in fatigue (D).

\section{DISCUSSION}

In the study of fatigue in muscles, nearly every group uses its own stimulation scheme to analyze the mechanism of fatigue, which makes comparison among different experiments difficult. In recent years, some investigators have realized that the mechanism of fatigue would be different depending on the type of stimulation. Two general types of stimulation have been used so far: one is repeated twitch stimulation, and the other is repeated tetanic stimulation. The mechanism of fatigue cannot be separated simply by the type of stimulation, and the principal causes are proposed to be different in the above two types of stimulation by some authors [16-18].

An understanding of the mechanism of the excitation-contraction coupling, especially concerning the transverse tubular system (T-tubular system), is of importance for the study of fatigue. The functional properties of the T-tubule membrane and their contribution to the action potential of the fiber have been discussed. Gage and Eisenberg [19] showed that action potential without contraction was recorded from a fiber in which the T-tubular system was disrupted and after-depolarization following action potential was absent after the disruption, suggesting that contraction 

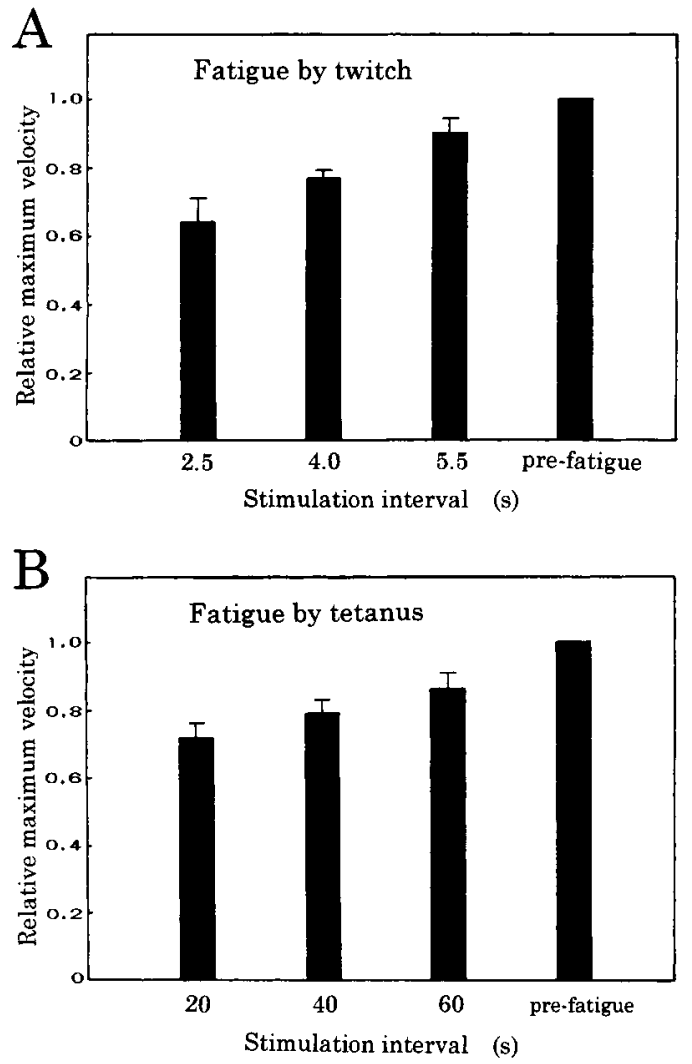

Fig. 8. The comparison of maximum shortening velocity measured by the slack test in twitch fatigue ( $A$, $2.5^{\circ} \mathbf{C}$ ) and tetanus fatigue $\left(\mathbf{B}, 16^{\circ} \mathbf{C}\right)$. The fatigue was developed by various stimulation intervals as shown in the figure. Each bar shows the mean and standard deviation $(n=4)$.

required an intact T-tubular system and its membrane might be excitable. Sugi and Ochi [20] and Sugi [21, 22] further indicated that some regenerating process participated in the inward spread of activation in frog fast-muscle, and that there was a mechanism in which the electrical current density causing depolarization of the T-tubule membrane was maximum at a point distant from the fiber surface.

In the present experiment, the high force developed by caffeine, which is generally thought to induce calcium release by acting directly upon the intracellular storage site, was observed after twitch fatigue (Fig. 5). This fact suggests that the decrease in force by twitch is largely attributable to the failure of activation of the fiber. The evidence in support of this view was provided by other authors [4, 17, 23, 24]. Edman and Lou [17] showed histologically that, in fibers fatigued by high-frequency twitch stimulation, the most peripheral layers of myofibrils remained strained but the center of the fiber showed marked waviness, indicating the failure of the inward spread of activation into the center of the muscle fibers. In a twitch-fatigued fiber, fre- quent stimulation is likely to cause the accumulation of potassium in the T-tubules when the stimulation interval is too brief to restore the concentration of potassium in the tubular fluid if the regenerative action potentials conduct along the T-tubular system as discussed above. The increased concentration of potassium may lead to depolarization of the tubular membrane [25] and will impair the inward spread of action potential along the T-tubules.

It is possible to estimate the time for potassium to diffuse out of the T-tubules after a twitch if the electrical and dimensional parameters of the T-tubules are available and experimental results can be compared with estimated values. The volume to surface ratio of the T-tubules is $1.25 \times 10^{-6} \mathrm{~cm}$ according to studies by electron microscopy [26, 27]. The electrical membrane capacity of the T-tubules is thought to be around $4 \mu \mathrm{F} / \mathrm{cm}^{2}$ [28] and the membrane is assumed to generate approximately the same amplitudes of action potential as that in the surface membrane. Using the above parameters, the concentration of potassium inside the T-tubles after single twitch is calculated to be $2.7 \mathrm{mM}$. The diffusion coefficient of potassium is $1.934 \times 10^{-9} \mathrm{~m}^{2} \mathrm{~s}^{-1}$ at $25^{\circ} \mathrm{C}$ at a concentration of $5 \mathrm{mM}$ $[29,30]$, from which the coefficient at each temperature is estimated by assuming that the coefficient is approximately proportional to the absolute temperature. The diffusion time is calculated by the equation $X=(D t)^{1 / 2}$, where $X, D$ and $t$ are distance, diffusion coefficient and time, respectively. The calculated time for potassium of $2.7 \mathrm{mM}$ to diffuse for the distance of $50 \mu \mathrm{m}$ is $1.40 \mathrm{~s}\left(0^{\circ} \mathrm{C}\right)$ and $1.30 \mathrm{~s}\left(20^{\circ} \mathrm{C}\right)$.

In the present results (Fig. 2), twitch stimulation at the interval of $1 \mathrm{~s}$ induced marked fatigue at low and high temperatures in accordance with the above estimated values. Fatigue by twitch, however, was also induced by stimulation at intervals longer than $1 \mathrm{~s}$ at low temperatures, and this fact is not explained by the above estimation. It is probable that, in the above calculation, potassium is supposed to diffuse freely in water, but the diffusion in a muscle fiber may be slower than the estimated velocity because of the curved T-tubules and the existence of ions other than potassium in the saline. The results in Fig. 2 show that fatigue at high temperatures is less marked than that at low temperatures. The faster diffusion may contribute to the weaker twitch fatigue at high temperatures. But the difference in the diffusion time in both temperature ranges on calculation is not large, whereas the difference in the force development in fatigue in both temperature ranges is very obvious. This discrepancy is probably due to the "staircase phenomenon," that the gradual increase in twitch force appeared soon 
after the start of stimulation at high temperatures and may obscure the fatigue induced by twitch at high temperatures.

The results of the length-force relation in a twitchfatigued fiber showing that the force on the ascending limb at low temperatures is lower than the control supplies additional evidence of the failure in activation during twitch fatigue (Fig. 6A). As the volume of the muscle fiber is constant, the diameter of the fiber increases when the length shortens; therefore, it is probable that the diffusion of potassium out of the Ttubules takes more time when the diameter is larger and this enhances twitch fatigue at lower temperatures because of slower diffusion. For example, if the sarcomere length decreases from 2.3 to $1.6 \mu \mathrm{m}$, the fiber radius increases from 50 to $60 \mu \mathrm{m}$ and the diffusion time at $0^{\circ} \mathrm{C}$ increases from 1.40 to $2.01 \mathrm{~s}$ on the calculation. This long diffusion time probably affects activation by twitch stimulation at the short sarcomere length, though some authors assume other mechanisms for the failure of the inward spread of activation $[9,31]$.

The time course of each twitch in fatigue showed that the rate of decay was slower, especially at low temperatures (Fig. 4A). The typical action potential in a skeletal muscle fiber is known to have what is called "after-depolarization," which is explained by the slow diffusion of potassium out of the T-tubules. Though in the present experiment the electrical phenomena were not measured, action potentials in twitch-fatigued fibers are supposed to have long after-depolarization, and it is probable that this depolarization might delay the decay of twitch force [3]. The maximum shortening velocity was shown to decrease in a twitch-fatigued fiber at low temperatures (Fig. 8). In this situation, as discussed above, the central myofibrils of the fibers are thought not to be activated; therefore, it is possible that the central part may introduce an extraload during shortening and decrease maximum shortening velocity.

On the other hand, the main cause of fatigue by tetanus is thought not to be the failure of activation but the reduced kinetics of cross-bridge function, or so-called "myofibrillar fatigue" [16, 17], which leads to reduced force production. This is indicated by the finding that the force developed by $15 \mathrm{mM}$ caffeine was nearly the same as that immediately before the application of caffeine and was lower than the initial force (Fig. 5B). This fact means that the contractile system was fully activated during tetanus fatigue and the further increase in calcium concentration by caffeine was not effective, and also suggests that stimulation leads to some metabolic changes within the mus- cle fiber that make myosin cross-bridges less capable of producing force. In confirmation of this view, the results in Fig. 3 demonstrate that the temperature-dependence of tetanus fatigue was contrary to that in twitch fatigue; namely, tetanus fatigue appeared sooner at the higher temperatures. At the higher temperatures, repeated tetani may lead to larger change in the concentration of intracellular substances; for example, reduction in phosphocreatine and ATP $[2,10$, 32], and accumulation of products of ATP hydrolysis such as ADP, Pi (phosphate) and $\mathrm{H}^{+}[11,12]$. These changes seem to bring about a decrease in the maximum shortening velocity (Fig. 8B) in addition to the decrease in force (Fig. 3) because experiments on skinned muscle fibers have established certain correlations between functions and increased concentrations of ATP hydrolysis products, ADP, $\mathrm{Pi}$ and $\mathrm{H}^{+}$. A lower $\mathrm{pH}$ has been shown to reduce both the maximum shortening velocity and maximum isometric force [13, 33], and increased $\mathrm{Pi}$ also reduced the isometric force [8]. The combined action of these hydrolysis products is thought to induce more marked tetanus fatigue at higher temperatures.

The authors would like to express their sincere thanks to Professor Haruo Sugi, Department of Physiology, Teikyo University School of Medicine, for making the versatile apparatus generously available and for his encouragement in the course of the experiment after the great disaster in Kobe. This work was partly supported by a Grant-in-Aid for Scientific Research from the Ministry of Education, Science, Sports and Culture of Japan to T. T.

\section{REFERENCES}

1. Gonzalez-Serratos $H$, Somlyo AV, McClellan G, Shuman $\mathrm{H}$, Borrero LM, and Somlyo AP: Composition of vacuoles and sarcoplasmic reticulum in fatigued muscle: electron probe analysis. Proc Natl Acad Sci USA 75: 1329-1333, 1978

2. Nassar-Gentina V, Passonneau JV, Vergara JL, and Rapoport SI: Metabolic correlates of fatigue and recovery from fatigue in single frog muscle fibers. J Gen Physiol 72: 593-606, 1978

3. Lännergren $\mathrm{J}$ and Westerblad $\mathrm{H}$ : Force and membrane potential during and after fatiguing, continuous highfrequency stimulation of single Xenopus muscle fibres. Acta Physiol Scand 128: 359-368, 1986

4. Lännergren $\mathrm{J}$ and Westerblad $\mathrm{H}$ : Maximum tension and force-velocity properties of fatigued, single Xenopus muscle fibres studied by caffeine and high $\mathrm{K}^{+}$. J Physiol (Lond) 409: 473-490, 1989

5. Allen DG, Lee JA, and Westerblad H: Intracellular calcium and tension during fatigue in isolated single muscle fibres from Xenopus laevis. J Physiol (Lond) 415: 627-652, 1989

6. Ashley CC and Moisescu DG: Effect of changing the composition of the bathing solutions upon the isometric 
tension-pCa relationship in bundles of crustacean myofibrils. J Physiol (Lond) 270: 627-652, 1977

7. Fabiato $A$ and Fabiato $\mathrm{F}$ : Effects of $\mathrm{pH}$ on the myofilaments and the sarcoplasmic reticulum of skinned cells from cardiac and skeletal muscles. J Physiol (Lond) 276: 233-255, 1978

8. Godt RE and Nosek TM: Changes of intracellular milieu with fatigue or hypoxia depress contraction of skinned rabbit skeletal and cardiac muscles. J Physiol (Lond) 412: 155-180, 1989

9. Gonzalez-Serratos H, Garcia M, Somlyo AV, Somlyo AP, and McClellan G: Differential shortening of myofibrils during development of fatigue. Biophys J 33: 224a, 1981

10. Edwards RHT, Hill DK, and Jones DA: Metabolic changes associated with the slowing of relaxation in fatigued mouse muscle. J Physiol (Lond) 251: 287-301, 1975

11. Dawson MJ, Gadian DG, and Wilkie DR: Muscular fatigue investigated by phosphorus nuclear magnetic resonance. Nature 274: 861-866, 1978

12. Dawson MJ, Gadian DG, and Wilkie DR: Mechanical relaxation rate and metabolism studied in fatiguing muscle by phosphorus nuclear magnetic resonance. J Physiol (Lond) 299: 465-484, 1980

13. Chase PB and Kushmerick MJ: Effects of pH on contraction of rabbit fast and slow skeletal muscle fibers. Biphys J 53: 935-946, 1988

14. Sugi $H$ and Tsuchiya T: Stiffness changes during enhancement and deficit of isometric force by slow length changes in frog skeletal muscle fibres. J Physiol (Lond) 490: 191-205, 1988

15. Ford LE, Huxley AF, and Simmons RM: Tension responses to sudden length change in stimulated frog muscle fibres near slack length. J Physiol (Lond) 269: 441-515, 1977

16. Edman KAP and Lou F: Changes in force and stiffness induced by fatigue and intracellular acidification in frog muscle fibres. J Physiol (Lond) 424: 133-149, 1990

17. Edman KAP and Lou F: Myofibrillar fatigue versus failure of activation during repetitive stimulation of frog muscle fibres. J Physiol (Lond) 457: 655-673, 1992

18. Westerblad H, Lee JA, Lännergren J, and Alllen DG: Cellular mechanisms of fatigue in skeletal muscle. Am J Physiol 261: C195-C209, 1991

19. Gage PW and Eisenberg RS: Action potential without contraction in frog skeletal muscle fibers with disrupted transverse tubules. Science 158: 1702-1703, 1967

20. Sugi $H$ and Ochi $R$ : The mode of transverse spread of contraction initiated by local activation in single frog muscle fibers. J Gen Physiol 50: 2167-2176, 1967

21. Sugi $\mathrm{H}$ : The mode of inward spread of activation in frog muscle fibres investigated by means of high-speed microcinematography. Proc Jpn Acad 49: 63-68, 1973

22. Sugi $\mathrm{H}$ : Inward spread of activation in frog muscle fibres investigated by means of high-speed microcenematography. J Physiol (Lond) 242: 219-235, 1974

23. Eberstein $A$ and Sandow A: Fatigue mechanisms in muscle fibres. In: The Effect of Use and Disuse on Neuromuscular Functions, ed. Gutman F and Hnik P, Nakladatelstvi Ceskoslovenske Akademie ved Praha, Prague, pp 515-526, 1963

24. Kanaya H, Takauji M, and Nagai T: Properties of caffeine and potassium-contractures in fatigued frog single twitch muscle fibers. Jpn J Physiol 33: 945-954, 1983

25. Hnik K, Holas M, Krekule I, Kriz N, Mejsnar J, Smiesko V, Ujec E, and Vyskocil F: Work-induced potassium changes in skeletal muscle and effluent venous blood assessed by liquid ion-exchanger microelectrodes. Pflügers Arch 362: 84-95, 1976

26. Peachey L: The sarcoplasmic reticulum and transverse tubules of the frog' sartorius. J Cell Biol 25: 209-231, 1965

27. Adrian $\mathrm{RH}$, Costantin LL, and Peachey LD: Radial spread of contraction in frog muscle fibres. J Physiol (Lond) 204: 231-257, 1969

28. Falk $G$ and Fatt $P$ : Linear electrical properties of striated muscle fibres observed with intracellular electrodes. Proc R Soc Lond B 160: 69-123, 1964

29. Robinson RA and Stokes $\mathrm{RH}$ : Electrolyte Solutions, Butterworths, London, pp 513-515, 1959

30. Moore WJ: Physical Chemistry, Prentice-Hall, Englewood Cliffs, pp 339-343, 1962

31. Sugi H, Ota T, and Tameyasu T: Development of the maximum isometric force at short sarcomere lengths in calcium-activated muscle myofibrils. Experientia 39: $147-148,1983$

32. Spande JJ and Schottelius BA: Chemical basis of fatigue in isolated mouse soleus muscle. Am J Physiol 219: 1490-1495, 1970

33. Cooke R, Franks K, Luciani GB, and Pate E: The inhibition of rabbit skeletal muscle contraction by hydrogen ions and phosphate. J Physiol (Lond) 395: 77-97, 1988 